\title{
Clinicopathological patterns and outcomes of urothelial bladder malignancies in Sri Lankan patients
}

\author{
Umesh Jayarajah ${ }^{1}$, Hilary Fernando ${ }^{1}$ Kasun Herath $^{1}$, Sanka Kuruppu ${ }^{1}$, Uditha Wickramanayaka ${ }^{1}$, \\ Indika Fernando ${ }^{1}$, Chandu de Silva ${ }^{2}$, Serozsha Goonewardena ${ }^{1}$
}

\begin{abstract}
Introduction Studies on bladder cancer in Sri Lanka have shown varying results in relation to clinicopathological characteristics and data on outcomes is limited. This study was aimed to describe the clinicopathological characteristics and outcomes of histologically confirmed urothelial bladder malignancies and to compare with previous studies.
\end{abstract}

Methods A retrospective analysis of prospectively collected data of 314 newly diagnosed primary bladder malignancies between January-2007 and January-2017, was performed. After excluding the non-urothelial cancers, 289 (92\%) urothelial cancers (males $=245$, $84.8 \%$, mean age $=65.4 \pm$ SD10.9 years) were analysed. Data on clinical presentation, cystoscopic findings, histopathology and outcomes were studied.

Results The majority $(87.9 \%, \mathrm{n}=254)$ presented with haematuria with a median duration of symptoms of 1 month. Non-muscle invasive cancers were seen among 64.4\% (pTa: $n=87$ (30.1\%), pT1: $n=99$ (34.3\%)). The pT1 high grade (pT1-HG) tumours were seen in $17.5 \%$. Muscle invasive bladder cancer (MIBC) were seen in $35.6 \%(n=103)$. The majority were high grade tumours $(n=156,54 \%)$. Urothelial MIBC were significantly associated with solid tumours $(p<0.001)$, high grade $(p<0.001)$ and size $>3 \mathrm{~cm}(p<0.001)$. Comparison with previous studies showed a decline in the proportion of MIBC while the pT1-HG tumours are on the rise. Of those followed up, 52.5\% developed recurrences with a median duration of 4 months (interquartile range (IQR): 3-12 months). Eighteen (9\%) progressed to a higher stage with a median duration of 17 months (IQR:3.75-41.75).

Conclusions Urothelial cancer in the study population was $92 \%$. Higher proportion of MIBC, high grade tumours and pT1-HG tumours were noted. The recurrence rate was high. Future studies should focus on the causative factors for this trend.

Ceylon Medical Journal 2020; 65: 105-111

DOI: http://doi.org/10.4038/cmj.v65i4.9281

\section{Introduction}

Bladder cancer is one of the commonest malignancies occurring worldwide [1]. It is the ninth most common cause of cancer for both sexes combined. It generally has a male preponderance (sex ratio worldwide: 3.5:1) [1]. Despite advances in treatment, outcome for muscle invasivebladder cancer has not improved significantly over the past decades [2].

According to the data collected and compiled by the National Cancer Control Programme of Sri Lanka (NCCPSL), bladder cancer is the tenth commonest cancer among Sri Lankan males [3]. There is no established comprehensive population-based registry for bladder cancer in Sri Lanka. The available data from Sri Lanka are limited and previous studies have shown varying results in relation to clinicopathological characteristics of bladder cancer in Sri Lanka and in neighbouring South Asian countries [3-14]. This may be due to inclusion of varying proportions of non-urothelial bladder cancers, which are more aggressive compared to urothelial cancers [15] .

The objective of this study was to identify the clinicopathological characteristics and outcome of urothelial bladder cancer treated at a tertiary care urology unit in Sri Lanka over a period of 10 years and to compare with similar studies in Sri Lanka. Furthermore, the key difference in our population compared to other regions is highlighted.

\section{Methods}

This is a retrospective analysis of prospectively collected data. All patients with newly diagnosed urothelial bladder cancer with histological confirmation at one of two urology units of National Hospital of Sri Lanka, Colombo, between January 2007 and December 2016 were analysed.

All patients underwent transurethral resection of the bladder tumour (TURBT) which was the standard procedure in the initial diagnosis and treatment of bladder

${ }^{1}$ Department of Urology, National Hospital of Sri Lanka, Colombo, Sri Lanka, ${ }^{2}$ Department of Pathology, Faculty of Medicine, University of Colombo, Sri Lanka.

Correspondence: UJ, e-mail: <umeshe.jaya@gmail.com>. Received 05 September 2020 and revised version 01 December 2020 accepted 02 December 2020.

This is an open-access article distributed under the terms of the Creative Commons Attribution License, which permits unrestricted use, distribution, and reproduction in any medium, provided the original author and source are credited. 
cancer [16]. All tumours with papillary configuration had complete resection and those with solid, and papillary/ solid (mixed) configuration had a near total debulking during TURBT. All patients underwent an ultrasound scan by a consultant radiologist experienced in urological imaging. All pathological analyses were performed by a single unit and the TURBTs were performed by the single urologist or by senior trainees under direct supervision. Data were collected prospectively at the time of hospital discharge/clinic visit on a separate file for each patient, rendering accurate documentation and easy retrieval. The clinical presentation, cystoscopic findings and histopathological findings (based on TURBT or radical cystectomy where available) were analysed. Pathological grading was assessed according to the World Health Organisation (WHO) and International Society of Urological Pathology (ISUP) classification 2004 [17]. Details of disease recurrence and the stage were recorded. The time to first recurrence, progression to muscle invasive disease, and the follow up period were documented. During the last 2 years of the study, those with a suspicion that the initial resection was incomplete and when the pathologist reported no muscle tissue in the specimen, a second transurethral resection (re-staging) was performed after 2 weeks. Other patients underwent periodic surveillance with check cystoscopy at 3, 6-9, 12 months and annually thereafter, if no recurrences were found and 3-6 monthly, if recurrence was detected.

Data were analysed using SPSS ${ }^{\circledR}$ software version 17 and were expressed in terms of frequency and percentages. Bivariate analyses were performed using the Chi-square test. Multivariate analyses were performed using binary logistic regression. A p $<0.05$ was considered statistically significant (18). Approval for the study was obtained from the Ethics Committee of National Hospital of Sri Lanka. Informed written consent was obtained from the participants prior to inclusion.

\section{Results}

A total of 314 newly diagnosed primary bladder cancer patients were identified during the study period. The 25 (8\%) non-urothelial cancers were excluded and 289 urothelial cancers (males $=245,84.8 \%$, mean age $=$ $65.4 \pm$ SD10.9 years) were analysed.

The majority presented with haematuria 254 (87.9\%) with a median duration of symptoms of 1 month (inter quartile range-IQR: 0.5-3). Other associated symptoms reported were supra pubic pain $(n=23,8 \%)$, loin pain $(n=15$, $5.2 \%)$ and passage of clots ( $n=140,48.4 \%)$. In 28 (9.7\%) patients, the tumour was detected incidentally. In the majority ( $n=265,91.7 \%$ ), the tumour was detectable ultrasonographically.
Cystoscopic assessment revealed that the majority of tumours were more than $3 \mathrm{~cm}$ in diameter ( $\mathrm{n}=180,62.3 \%$ ). Most were solitary tumours ( $n=199,68.9 \%)$ and the rest were multifocal tumours ( 2 tumours: $n=42,14.5 \%, 3$ tumours: $n=22,7.6 \%$, > 3 tumours: $n=26,9 \%$ ). The majority were papillary tumours $(n=159,55 \%)$ and $22.5 \%(n=65)$ were solid tumours and $22.5 \%(n=65)$ had mixed tumours (both papillary and solid components). Most tumours were located in the lateral wall of the bladder $(72 \%, \mathrm{n}=208)$ and $24(8.3 \%)$ were bilateral. We noted that $26.3 \%(n=76)$ involved the trigone, $22.1 \%(\mathrm{n}=64)$ the bladder neck, $18 \%$ $(n=52)$ the anterior wall, 33.2\% $(n=96)$ the posterior wall, and $10.4 \%(n=30)$ the dome of the bladder.

Histological assessment revealed that $30.1 \%(n=87)$ and $34.3 \%(n=99)$ of the patients were found to have pTa and pT1 tumour respectively. The pT1 high grade tumours were seen in $17.5 \%(n=55)$ of all bladder tumours. Muscle invasive bladder cancer (MIBC) (pT2 and above) was seen in $35.6 \%(n=103)$. High grade and lymphovascular invasion were seen among 54\% (n=156) and 19 (6.6\%) patients respectively. Few patients $(n=7)$ had variants of urothelial carcinomas. Three patients had squamous components. One patient each had poorly differentiated and focal neuroendocrine pattern, mixed glandular elements, squamous and sarcomatoid components, and florid Von Brunn nests.

Analysis and comparison between urothelial MIBC and non-muscle invasive bladder cancer (NMIBC) is given in table 1. Significant associations with MIBC were solid configuration of tumours $(\mathrm{p}<0.001)$, high grade tumours $(p<0.001)$, size $>3 \mathrm{~cm}(\mathrm{p}<0.001)$, solitary tumours $(\mathrm{p}=0.032)$, lymphovascular invasion $(\mathrm{p}<0.001)$ and presence of hydronephrosis in ultrasonography $(\mathrm{p}<0.001)$ (Table 1$)$. In the multivariate analysis, only solid configuration, high grade and lymphovascular invasion were found to be significant (Table 2).

All 289 patients underwent an initial TURBT and follow up check cystoscopies. Only 2 patients with MIBC underwent radical cystectomy. Of the study participants, 89 patients were lost to follow up. Of the remaining 200 patients, the median follow up period was 18.5 months (IQR:5-46.75). A total of 105 (52.5\%) patients developed recurrences with a median duration of 4 months (IQR: 3-12 months). Eighteen (9\%) progressed to a higher stage with a median duration of 17 months (IQR: 3.75-41.75). The follow up details for MIBC and NMIBC are given in table 3 . Of the pT1 high grade tumours $(n=55), 10$ were lost to follow up. Of the remaining patients $(n=45)$, the median follow up period was 15 months (IQR: 4-27). Around 62.2\% $(n=28)$ developed recurrences with a median duration of 3 months (IQR: 2-6) and 17.8\% (n=8) developed progression with a median duration of 12 months (IQR: 3-21). 
Table 1. Comparison between MIBC and NMIBC

\begin{tabular}{|c|c|c|c|c|c|c|}
\hline & & \multicolumn{2}{|c|}{$M I B C$} & \multicolumn{2}{|c|}{ NMIBC } & \multirow[t]{2}{*}{$p$ value } \\
\hline & & $N$ & $\%$ & $N$ & $\%$ & \\
\hline \multirow[t]{2}{*}{ Gender } & Male & 84 & $81.6 \%$ & 161 & $86.6 \%$ & 0.257 \\
\hline & Female & 19 & $18.4 \%$ & 25 & $13.4 \%$ & \\
\hline Mean age (years) & & \multicolumn{2}{|c|}{$65.02 \pm \mathrm{SD} 11.41$} & \multicolumn{2}{|c|}{$65.63 \pm S D 10.66$} & 0.65 \\
\hline \multirow[t]{2}{*}{ Haematuria } & Yes & 89 & $86.4 \%$ & 165 & $88.7 \%$ & 0.566 \\
\hline & No & 14 & $13.6 \%$ & 21 & $11.3 \%$ & \\
\hline \multicolumn{2}{|l|}{ Mean duration of symptoms (months) } & \multicolumn{2}{|c|}{$2.49 \pm \mathrm{SD} 3.40$} & \multicolumn{2}{|c|}{$2.47 \pm$ SD 4.79} & 0.96 \\
\hline \multirow[t]{2}{*}{ Suprapubic pain } & yes & 11 & $10.8 \%$ & 12 & $6.5 \%$ & 0.195 \\
\hline & no & 91 & $89.2 \%$ & 174 & $93.5 \%$ & \\
\hline \multirow[t]{2}{*}{ Loin pain } & yes & 6 & $5.8 \%$ & 9 & $4.8 \%$ & 0.717 \\
\hline & no & 97 & $94.2 \%$ & 177 & $95.2 \%$ & \\
\hline \multirow[t]{2}{*}{ Incidental } & yes & 11 & $10.7 \%$ & 17 & $9.1 \%$ & 0.672 \\
\hline & no & 92 & $89.3 \%$ & 169 & $90.9 \%$ & \\
\hline \multirow[t]{2}{*}{ Hydronephrosis in ultrasonography } & yes & 37 & $38.1 \%$ & 28 & $15.6 \%$ & $<0.001$ \\
\hline & no & 60 & $61.9 \%$ & 151 & $84.4 \%$ & \\
\hline \multirow[t]{2}{*}{ Size } & $<3 \mathrm{~cm}$ & 18 & $17.6 \%$ & 89 & $48.1 \%$ & $<0.001$ \\
\hline & $>3 \mathrm{~cm}$ & 84 & $82.4 \%$ & 96 & $51.9 \%$ & \\
\hline \multirow[t]{2}{*}{ Tumour configuration } & papillary & 25 & $24.3 \%$ & 134 & $72.0 \%$ & $<0.001$ \\
\hline & solid or mixed & 78 & $75.7 \%$ & 52 & $28.0 \%$ & \\
\hline \multirow[t]{2}{*}{ Focality } & solitary & 79 & $76.7 \%$ & 120 & $64.5 \%$ & 0.032 \\
\hline & multiple & 24 & $23.3 \%$ & 66 & $35.5 \%$ & \\
\hline \multirow[t]{2}{*}{ Tumour grading } & High Grade & 98 & $95.1 \%$ & 58 & $31.2 \%$ & $<0.001$ \\
\hline & Low Grade & 5 & $4.9 \%$ & 128 & $68.8 \%$ & \\
\hline \multirow[t]{2}{*}{ Lymphovascular invasion } & yes & 15 & $15.8 \%$ & 4 & $2.2 \%$ & $<0.00$ \\
\hline & no & 80 & $84.2 \%$ & 178 & $97.8 \%$ & 1 \\
\hline
\end{tabular}

Table 2. Multivariate analysis of factors associated with occurrence of MIBC

\begin{tabular}{|c|c|c|c|c|c|c|}
\hline \multirow[t]{2}{*}{ Factors } & \multirow[t]{2}{*}{$B$} & \multirow[t]{2}{*}{ Bias } & \multirow[t]{2}{*}{ Std. Error } & \multirow[t]{2}{*}{$P$ value } & \multirow{2}{*}{$\begin{array}{c}95 \% \\
\text { Interval } \\
\text { Lower }\end{array}$} & \multirow{2}{*}{$\begin{array}{c}\text { Confidence } \\
\text { Upper }\end{array}$} \\
\hline & & & & & & \\
\hline Hydronephrosis & .345 & -.019 & .363 & .329 & -.367 & 1.045 \\
\hline Size $>3 \mathrm{~cm}$ & .745 & .004 & .432 & .069 & -.060 & 1.643 \\
\hline Solid components & .906 & .038 & .371 & .011 & .231 & 1.655 \\
\hline Multifocality & -.463 & -.017 & .394 & .213 & -1.232 & .283 \\
\hline High grade & 3.215 & .234 & 1.259 & .001 & 2.418 & 4.902 \\
\hline Lymphovascular invasion & 1.495 & .403 & 2.276 & .007 & .402 & 3.342 \\
\hline Constant & -2.243 & -.403 & 2.292 & .001 & -4.346 & -1.078 \\
\hline
\end{tabular}

MIBC: Muscle invasive bladder cancer, NMIBC: Non-muscle invasive bladder cancer 
Table 3. Follow up and outcomes of urothelial bladder cancers

\begin{tabular}{|c|c|c|c|c|c|c|c|}
\hline & $\begin{array}{l}\text { Lost to } \\
\text { follow up } \\
(\mathrm{N} / \%)\end{array}$ & $\begin{array}{l}\text { Followed up } \\
(\mathrm{N} / \%)\end{array}$ & $\begin{array}{l}\text { Total follow } \\
\text { up duration: } \\
\text { Median (IQR) } \\
\text { months }\end{array}$ & $\begin{array}{l}\text { Recurrence } \\
\text { rate } \\
(\mathrm{N} / \%)\end{array}$ & $\begin{array}{l}\text { Recurrence free } \\
\text { survival: } \\
\text { Median } \\
(I Q R) \text { months }\end{array}$ & $\begin{array}{l}\text { Progression } \\
\text { rate } \\
(\mathrm{N} / \%)\end{array}$ & $\begin{array}{l}\text { Progression } \\
\text { free survival: } \\
\text { Median (IQR) } \\
\text { months }\end{array}$ \\
\hline MIBC & $55(53.4 \%)$ & $48(46.6 \%)$ & 8 (IQR: 3 - 21) & $20(41.7 \%)$ & 5 (IQR: 2 - 8) & Not applicable & Not applicable \\
\hline NMIBC & 34 (18.3\%) & $152(81.7 \%)$ & 25 (IQR: 6 - 50) & 85 (55.9\%) & 4 (IQR: 3 - 12) & $18(11.8 \%)$ & 17 (IQR: 4 - 41) \\
\hline Pt1HG & $10(18.5 \%)$ & 45 (81.5\%) & 15 (IQR: 4 - 27) & $28(62.2 \%)$ & 3 (IQR: $2-6)$ & $8(18.2 \%)$ & 12 (IQR: $3-21)$ \\
\hline
\end{tabular}

MIBC: Muscle invasive bladder cancer, NMIBC: Non-muscle invasive bladder cancer, HG: High grade

\section{Discussion}

This study describes the clinical and pathological characteristics of urothelial bladder cancers in a single urology unit over a period of ten years. The mean age and the age distribution of this study population is comparable to previous studies (table 4 (3-9)). The mean/ median age has been similar during the past two decades and is comparable to studies from the nearby countries. The median age of bladder cancer in India was 65-70 years while in Pakistan was 58 years which were comparable to our country $[10,11]$. The present study showed a considerably high male preponderance (male:female=5.6) similar to previous studies in Sri Lanka whereas in the Western countries it is reported as 3.5:1 [1]. A similar high male preponderance was seen in India (86.4\% male vs. $13.6 \%$ female) which is attributed to the low prevalence of smoking among South Asian females compared to the Western world [10].

As expected, muscle invasive tumours were significantly associated with solid configuration, high grade tumours, size $>3 \mathrm{~cm}$, hydronephrosis and lymphovascular invasion. The association with hydronephrosis is probably due to the local invasion to the intravesical part of the ureter which is possible in muscle invasive disease. However, 15.6\% of NMIBC also had hydronephrosis. The reason for this finding is unclear. Partial obstruction of the vesicoureteric junction by the tumour or the oedema caused by inflammation may be probable explanations.

The proportion of urothelial tumours in our study cohort was $92 \%$. The proportion of non-urothelial tumours are considerably higher (8\%) compared to India and Pakistan 3-4\% [10, 11]. Such non-urothelial bladder cancers are aggressive in nature and associated with poor survival [19-21]. Although the reason remains unclear, Sasikumar et al has suggested that the common use of agrochemicals and pesticides used in the semiurban and the rural community may be a possible explanation [9].
The proportion of MIBC in the present study was $35.6 \%$ which is considerably high compared to a recent analysis in India which showed only 26\% [10]. However, compared to a similar study conducted in 1993-2000 in the same urology unit, there is a considerable reduction from $48.4 \%$ to $37 \%$. This may indicate early diagnosis through better health care facilities. The proportion of high grade tumours is considerably high (54\%) compared to Western data (27\%) [2]. The above findings may be due to the innately aggressive nature of urothelial tumours in our population or due to variations in reporting [22]. Our study did not detect any cases of carcinoma in situ (CIS). A previous study showed only 1 CIS among NMIBC and Cancer Registry data from 2001 to 2005 showed only 10 cases (1.9\%) of CIS (Table S1) [9]. Furthermore, none of the other published studies from Sri Lanka showed any cases of primary CIS, highlighting the rarity of CIS in this country.

Despite the relatively low follow up period, the recurrence rate is considerably higher than the Western data, with a low recurrence free survival [23]. The nonavailability of intravesical chemotherapy which should ideally be administered within 24 hours after the first TURBT may be a major reason [23]. Compared to the neighbouring region and Western studies, we noted a high incidence of pT1 high grade tumours (17.5\%), which is showing an increasing trend (table S1) [14, 24, 25]. Change in the pathological grading systems from 1973 WHO classification to 2004 ISUP/WHO classification and early detection of aggressive tumours before progressing to MIBC are possible reasons $[9,17]$. A higher proportion of MIBC who were referred to adjuvant therapy were lost to follow up. This may be a reflection of the large catchment population of the institution (over 8 million) and the long distances travelled by patients to receive treatment. Also, the stigma associated with cancer and socioeconomic difficulties in travelling to obtain adjuvant therapy may have also contributed. 
Table 4. Comparison with previous studies in Sri Lanka

\begin{tabular}{|c|c|c|c|c|c|c|c|c|c|c|c|c|}
\hline Time & $\begin{array}{l}1993- \\
2000\end{array}$ & $\begin{array}{l}2000- \\
2001\end{array}$ & $\begin{array}{l}2001- \\
2005\end{array}$ & 2006 & 2007 & 2008 & 2009 & 2009 & 2010 & 2010 & $\begin{array}{l}2011- \\
2014\end{array}$ & $\begin{array}{l}2007- \\
2016\end{array}$ \\
\hline Authors & $\begin{array}{l}\text { Goonewar- } \\
\text { dena }^{3}\end{array}$ & Perera $^{4}$ & $\begin{array}{l}\text { Rana- } \\
\text { singhe }^{5}\end{array}$ & $\begin{array}{l}\text { NCCP } \\
\mathrm{SL}^{6}\end{array}$ & $\begin{array}{l}\mathrm{NCCP} \\
\mathrm{SL}^{7}\end{array}$ & $\begin{array}{l}\mathrm{NCCP}^{5} \\
\mathrm{SL}^{15}\end{array}$ & $\begin{array}{l}\text { NCCP } \\
\mathrm{SL}^{16}\end{array}$ & $\begin{array}{l}\text { Sathe- } \\
\operatorname{san}^{8}\end{array}$ & $\begin{array}{l}\text { Pra- } \\
\text { bath }^{9}\end{array}$ & $\begin{array}{l}\mathrm{NCCP} \\
\mathrm{SL}^{2}\end{array}$ & $\begin{array}{l}\text { Sasik- } \\
\text { umar }^{10}\end{array}$ & $\begin{array}{l}\text { Present } \\
\text { study }\end{array}$ \\
\hline Male: female & $5.5: 1$ & $9: 1$ & $4: 1$ & $3: 1$ & $3.2: 1$ & $5.2: 1$ & $5.1: 1$ & $3.1: 1$ & $3.7: 1$ & $4.8: 1$ & $4.1: 1$ & $5.6: 1$ \\
\hline Mean age & 64 & NA & $\begin{array}{l}\text { Median } \\
62-64\end{array}$ & $\begin{array}{l}\text { Median } \\
60-64\end{array}$ & $\begin{array}{l}\text { Median } \\
65-69\end{array}$ & $\begin{array}{l}\text { Median } \\
65-69\end{array}$ & $\begin{array}{l}\text { Median } \\
60-64\end{array}$ & $\begin{array}{l}\text { Median } \\
65\end{array}$ & $\begin{array}{l}\text { Median } \\
67.5\end{array}$ & $\begin{array}{l}\text { Median } \\
65-69\end{array}$ & 65 & 65.4 \\
\hline Total & 301 & 139 & 637 & 131 & 151 & 280 & 311 & 35 & 33 & 335 & 148 & 314 \\
\hline Urothelial & $93.4 \%$ & $96 \%$ & $72 \%$ & $69.5 \%$ & $79 \%$ & $82.5 \%$ & $82.6 \%$ & $97 \%$ & $90.9 \%$ & $85 \%$ & $89.2 \%$ & $92 \%$ \\
\hline Squamous & $3 \%$ & NA & $9 \%$ & $9 \%$ & $8 \%$ & $4 \%$ & $5.4 \%$ & $0 \%$ & $6.1 \%$ & $4.5 \%$ & $8.1 \%$ & $3.2 \%$ \\
\hline Adeno-carcinoma & $1.3 \%$ & NA & $3 \%$ & $5 \%$ & $4 \%$ & $4.2 \%$ & $4.1 \%$ & $0 \%$ & $0 \%$ & $3.3 \%$ & $1.4 \%$ & $2.9 \%$ \\
\hline Mesenchymal tumours & $2.3 \%$ & NA & NA & $2.3 \%$ & $1.3 \%$ & None & $1 \%$ & $0 \%$ & $3 \%$ & None & $0.7 \%$ & $1.3 \%$ \\
\hline MIBC & $48.4 \%$ & $30.9 \%$ & $94 \%$ & NA & NA & NA & NA & $37.3 \%$ & $21.2 \%$ & NA & $35 \%$ & $37 \%$ \\
\hline CIS & None & NA & $1.90 \%$ & NA & NA & NA & NA & None & None & NA & $0.70 \%$ & None \\
\hline PT1 HG & $5.3 \%$ & NA & NA & NA & NA & NA & NA & $3 \%$ & $18 \%$ & NA & $16.5 \%$ & $17.5 \%$ \\
\hline
\end{tabular}

NA: Not available, HG: High grade, CIS: Carcinoma in situ, MIBC: Muscle invasive bladder cancer, NCCPSL: National Cancer Control Program Sri Lanka

A comprehensive bladder cancer registry is essential to analyse the clinicopathological and survival patterns of patients. Sri Lanka, being a developing country with limited resources and free healthcare system needs a comprehensive epidemiological survey for proper distribution of the available resources. An analysis of cancer registry showed the prevalence of muscle invasive disease to be $94 \%$ which is very high compared to the hospital based data [6] (table 4). In 2010, the age standardised incidence rate for males was 3.0 per 100000 and it was the tenth commonest cancer in males. Based on our findings, early tumours may be missed and the true incidence may be much higher. Therefore, there is a compelling need for a comprehensive population based database for bladder cancer. Until such time, individual hospital based data should also be compared with nationwide trends together with the National Cancer Registry for the planning of healthcare policies and resource allocation.

There are important differences in our population compared to the Western world. In our study population, a considerable proportion had high grade cancers. Furthermore, higher proportion of pT1 high grade tumours with high recurrence rates were also noted. The higher proportion of muscle invasive bladder tumours may be due to the delayed presentation or the aggressive nature of the tumour.

\section{Limitations}

It is a retrospective analysis from a single tertiary care urology unit. Lack of data on risk factors such as smoking and occupational history and follow up precluded a detailed analysis on causative factors and survival.

\section{Conclusion}

Urothelial cancer in the study population was $92 \%$ with $35.6 \%$ having muscle invasive disease. We noticed a substantial proportion of muscle invasive and high grade cancers with high recurrence rates compared to the neighbouring region and the Western world. Over the last two decades, the proportion of muscle invasive bladder cancer is declining while the pT1 high grade tumours are on the rise. Future studies should focus on the causative factors for this trend. Furthermore, deficiencies in the reporting in national cancer database is highlighted and there is a compelling need for a comprehensive population based database for bladder cancers in Sri Lanka. The changes in the patterns of urothelial cancers in hospital based data together with the National Cancer Registry should be considered prior to allocation of resources. 


\section{Abbreviations}

NCCPSL: National Cancer Control Program Sri Lanka

TURBT: Transurethral resection of bladder tumour

WHO: World Health Organisation

ISUP: International Society for Urological Pathology

SPSS: Statistical Package for Social Sciences

IQR: Inter-quartile range

MIBC: Muscle invasive bladder cancer

NMIBC: Non-muscle invasive bladder cancer

BCG: Bacillus Calmette-Guerin

CIS: Carcinoma in situ

\section{Declarations}

Ethics approval and consent to participate: Ethical approval was obtained from the Ethics Review Committee of the National Hospital of Sri Lanka (AAJ/ETH/COM/ 2017-13). Informed written consent was taken from the participants prior to entering in the database.

Consent for publication: Not applicable.

Availability of data and materials: The datasets generated and analysed during the current study are available from the corresponding author on reasonable request.

Competing interests: The authors declare that they have no competing interests.

Funding: None.

Acknowledgements: None.

\section{References}

1. Ferlay J, Soerjomataram I, Dikshit R, Eser S, Mathers C, Rebelo M, et al. Cancer incidence and mortality worldwide: sources, methods and major patterns in GLOBOCAN 2012. Int J Cancer 2015; 136(5): E359-86

2. Wallace D, Bryan R, Dunn J, Begum G, Bathers S. Delay and survival in bladder cancer. BJU Int. 2002; 89(9): 86878 .

3. Ministry of Health Sri Lanka. Cancer Incidence Data, National Cancer Control Programme, Sri Lanka 2020. Available from: http:/ghdx.healthdata.org/organizations/ national-cancer-control-programme-ministry-health-srilanka.

4. Goonewardena S, De Silva W, De Silva M. Bladder cancer in Sri Lanka: experience from a tertiary referral center. Int $J$ Urol. 2004; 11(11): 969-72.

5. Perera N. Characterisation of a bladder cancer cohort in a urological unit. Ceylon Med J. 2011; 47(3): 102.

6. Ranasinghe WK, De Silva D, De Silva M, Ranasinghe TI,
Lawrentschuk N, Bolton D, et al. Incidence of bladder cancer in Sri Lanka: analysis of the cancer registry data and review of the incidence of bladder cancer in the South Asian population. Korean J Urol. 2012; 53(5): 304-9.

7. Sathesan B, Prabath A, Goonewardena S. Urological malignancies: one-year audit from a tertiary referral centre. Sri Lanka J Urol. 2010; 10(1): 24-7.

8. Prabath A, Goonewardena S. Pattern of urological malignancies in 2010 - an audit from a tertiary referral centre. Sri Lanka J Urol. 2012; 11(1): 30-5.

9. Sasikumar S, Wijayarathna KSN, Karunaratne KAMS, Gobi U, Pathmeswaran A, Abeygunasekera AM. Pathological Characteristics of Primary Bladder Carcinoma Treated at a Tertiary Care Hospital and Changing Demographics of Bladder Cancer in Sri Lanka. Adv Urol. 2016; 5751647

10. Yuvaraja TB, Waigankar S, Bakshi G, Prakash G. Genitourinary cancers: Summary of Indian data. South Asian J Cancer. 2016; 5(3): 122-4.

11. Rafique M, Javed AA. Clinico-pathological features of bladder carcinoma: experience from a tertiary care hospital of Pakistan. Int Urol Nephrol. 2006; 38(2): 247-50.

12. Goonewardena SA, Jayarajah U, de Silva MC, Kuruppu SN, Fernando DH, Herath KB. Bladder cancer in women: a Sri Lankan study. Ceylon Med J. 2019; 64(3): 98-102.

13. Jayarajah U, Herath K, Fernando M, Kuruppu S, Wickramanayaka U, Fernando I, et al. A clinico-pathological study of non-urothelial bladder cancers in a cohort of patients from a tertiary care urology unit in Sri Lanka. Ceylon Med J. 2018; 63(2): 92-4.

14. Laishram RS, Kipgen P, Laishram S, Khuraijam S, Sharma DC. Urothelial tumors of the urinary bladder in Manipur: a histopathological perspective. Asian Pac J Cancer Prev. 2012; 13(6): 2477-9.

15. Dahm P, Gschwend JE. Malignant non-urothelial neoplasms of the urinary bladder: a review. Eur Urol. 2003; 44(6): 672-81.

16. Goonewardena S, de Silva C, Jayarajah U, de Silva V, Sathesan B, Pathirathne P, et al. Detrusor muscle in the initial TURBT specimen and recurrence rate at first check cystoscopy in non-muscle invasive bladder cancer. Sri Lanka J Surg. 2020; 38(1): 23-7.

17. Cheng L, MacLennan GT, Lopez-Beltran A. Histologic grading of urothelial carcinoma: a reappraisal. Hum Pathol. 2012; 43(12): 2097-108.

18. Gunaratne A, Jayarajah U, Abeygunasekera A. Continuing metamorphosis of evidence-based medicine: the past, present and the future. Galle Med J. 2020; 25(4): 118-21.

19. Fernando MH, Jayarajah U, Herath KB, de Silva MVC, Goonewardena SAS. Aggressive squamous cell carcinoma 
of the bladder associated with a history of large bladder stone -w a case report. Clin Case Rep. 2017; 5(10): 1616.

20. Jayarajah U, Fernando MH, Herath KB, de Silva VC, Goonewardena SAS. Partial cystectomy for a primary locally advanced leiomyosarcoma of the bladder: a case report and review of the literature. Clin Case Rep. 2018; 6(5): 883.

21. Jayarajah U, Fernando D, Herath KB, de Silva M, Goonewardena S. Primary signet-ring cell adenocarcinoma of the urinary bladder treated with partial cystectomy: a case report and review of the literature. Case Rep Urol. 2017: 6829692.

22. Jayarajah U, Fernando M, Herath K, Kuruppu S, Wickramanayaka U, Fernando I, et al. Clinico-pathological characteristics and outcome of upper urinary tract urothelial carcinoma presenting to a tertiary care urology unit in Sri Lanka. Ceylon Med J. 2018; 63(3): 129-32.

23. Logan C, Brown M, Hayne D. Intravesical therapies for bladder cancer - indications and limitations. BJU Int. 2012; 110 Suppl 4: 12-21.

24. Peyromaure M, Guerin F, Amsellem-Ouazana D, Saighi D, Debre B, Zerbib M. Intravesical bacillus Calmette-Guerin therapy for stage T1 grade 3 transitional cell carcinoma of the bladder: recurrence, progression and survival in a study of 57 patients. J Urol. 2003; 169(6): 2110-2.

25. Margel D, Tal R, Golan S, Kedar D, Engelstein D, Baniel J. Long-term follow-up of patients with Stage T1 high-grade transitional cell carcinoma managed by Bacille CalmetteGuerin immunotherapy. Urol. 2007; 69(1): 78-82. 